\section{E-mail: Silvia.Schnitzler@gmx.de}

Odorants are low-boiling compounds such as esters, ketones or ethers [1]. Their structures in the gas phase may be studied by microwave spectroscopy [2]. Odorants are active in condensed phase, and hence their solid-state structures are of interest, too. In addition to in situ crystallization [3], one can imagine two alternative strategies to achieve the determination of their crystal structures despite their volatility.

a) The synthesis of clathrates. In this process the odorants are enclosed in the cavities of a host crystal. We have cocrystallized several ethers and ketones with cholesteric acid [4] and obtained mixed crystals of remarkably high quality: Single crystals of the inclusion compound allylacetate in cholesteric acid gave a well-resolved data set $(\sin \theta / \lambda=1.15$ $\AA^{-1}$ ) sufficient for multipole refinement [5].

b) Coordination of the odorant to a Lewis acid. In order to identify suitable cations as coordination partners and appropriate synthetic procedures, we searched the CSD [6] for simple coordinated solvent Lewis bases such as acetone or diethylether. Dinuclear Ag carboxylates [7] or $\mathrm{Cu}$ (II) complexes in which the equatorial coordination sites are occupied by preferably small ligands such as dimethylethylendiamine [8] represent promising candidates for binding the target molecules in axial positions. We will attempt to coordinate more complex odorants to the same chemical systems and study the resulting Lewis acid-base adducts.

[1] Kraft P., Bajgrowicz J. A., Denis C., Fráter G., Angew. Chem. Int. Ed. 2000, 39, 2980. [2] Jelisavac D., Cortes Gomez D. C., Nguyen H. V. L., Sutikdja L. W., Stahl W., Kleiner I., J. Mol. Spect., 2009, 257, 111. [3] Boese R., Nussbaumer M., in Correlations, Transformations, and Interactions in Organic Crystal Chemistry, 1994, 7, 20. [4] Nakano K., Katsuta M., Sada K., Miyata M., CrystEngComm, 2001, 11, 1. [5] Volkov A., Macchi P., Farrugia L. J., Gatti C., Mallison P. R., Richter T., Koritsanszky T., XD2006. University of New York at Buffalo, USA 2006. [6] Allen F., Acta Crystallogr. Sect. B, 2002, 58, 380. [7] Wang Y., Englert U., manuscript submitted. [8] Akitsu T., Einaga Y., Acta. Crystallogr. Sect C, 2004, 60, 162.

Keywords: inclusion compounds, organic and inorganic coordination compounds, conformation, charge density

\section{FA4-MS34-P33}

Synthesis, Structures and Characterization of Diorganotin complexes. See Mun, Lee ${ }^{\mathrm{a}}$, Mohd. Ali, H., Kong Mun, Lo ${ }^{\mathrm{b}}$, ${ }^{\mathrm{a}}$ Department of Chemistry, University of Malaya, Kuala Lumpur, Malaysia

E-mail: smlee@um.edu.my

Metal complexes are widely prepared and have been successfully used in the treatment of numerous human diseases including cancer. Among the many metal complexes, organotin complexes have been widely studied for their biological activities such as anticancer, antihistamine, antifungal, biocides and anti-fouling. Schiff base derived from substituted 2-hydroxyacetophenone has been widely used as polydentate ligands in the preparation of metal complexes. In the present studies, a series of Schiff base ligands were prepared by reacting 3-hydroxy-2-naphthoic hydrazide with substituted 2-hydroxyacetophenone. The diorganotin complexes were subsequently prepared by adding the ligands with diorganotin dichloride or oxide in 1:1 molar ratio and were characterized by various spectroscopic methods including IR, NMR spectroscopies. The x-ray structures of some of the diorganotin complexes namely $\{[1-(5$-bromo-2oxidophenyl)ethylidene]-3-hydroxy-2naphthohydrazidato dimethyltin(IV), oxidophenyl)ethylidene]-3-hydroxy-2naphthohydrazidato dibutyltin(IV), oxidophenyl)ethylidene]-3-hydroxy-2naphthohydrazidato dimethyltin(IV) oxidophenyl)ethylidene]-3-hydroxy-2-

$\{[1-(5-b r o m o-2-$ $\{[1-(5-$ chloro-2and $\{[1-(5-$-chloro-2naphthohydrazidato dibutyltin(IV). All the complexes were found to be isostructures and the tin atom in each of the complexes is in a distorted cis- $\mathrm{C}_{2} \mathrm{NO}_{2} \mathrm{Sn}$ trigonal-bypyrimidal coordination. The deprotonated ligand is coordinated as tridentate via the azomethine nitrogen and two phenoxo oxygens. The tridentate 5-bromo-7-methylsalicylideneaminato(3-hydroxy-2-naphthohydrazidate) and 5chloro-7-methylsalicylideneaminato(3-hydroxy-2-

naphthohydrazidate) dianion of each of the complexes are stabilized by an intramolecular hydrogen bonding $\mathrm{O}-\mathrm{H}-\mathrm{N}$. The distortion from the trigonal-bypyrimidal coordination is influenced by the presence of the $\mathrm{R}$ groups.

Keywords: crystal structure, isostructure, organotin

\section{FA4-MS34-P34}

Complexation Properties of Completely Reduced meso-Octamethylporphyrinogens (Calix[4]pyrroles). Helen Stoeckli-Evans, ${ }^{\mathrm{a}}$ Guillaume Journot ${ }^{\mathrm{b}}$, Frédéric Bruyneel $^{\mathrm{b}}$, Reinhard Neier ${ }^{\mathrm{b}}$, ${ }^{a}$ Insitut de Physique, Université de Neuchâtel, Switzerland, ${ }^{\mathrm{b}}$ Insitut de Chimie, Université de Neuchâtel, Switzerland E-mail: helen.stoeckli-evans@unine.ch

Calixpyrroles bind anions efficiently and can be transformed into transition-metal complexes only under forcing conditions. Reducing the macrocycle creates a ligand that easily forms classical Werner complexes with copper, nickel, palladium, and iron ions. The metal complexes present an array of four directed hydrogen bonds, which specifically bind the counterions $[1,2]$

The reaction of the reduced macrocycle with iron triflate has produced some surprises. One complex exhibits a phase change at $173 \mathrm{~K}$, transforming from a monoclinic system $\left(Z^{\prime}=\right.$ 1) to a triclinic system $\left(Z^{\prime}=2\right)$. The triclinic phase appears to be a twinned crystal, which on heating reverts cleanly to the monoclinic non-twinned crystal. The question is posed, at 173 $\mathrm{K}$ is the crystal really twinned or simply split? Can image plates lie?

[1] Blangy, V., Heiss, C., Khlebnikov, V., Letondor, C., StoeckliEvans, H., Neier, R., Angew. Chem. Int. Ed. 2009, 48, 1688. [2] Journot, G., Letondor, D., Neier, R., H. Stoeckli-Evans, H., D. Savoia, D., Gualandi, A., Chem. Eur. J. 2010, 16, 4224.

Keywords: macrocyclic complexes, phase transformation, twinning

\section{FA4-MS34-P35}

Synthesis, Crystal Structure and Magnetic Properties of a Novel di- $\mu_{2}$-Alkoxo Bridged Binuclear Manganese(III) Schiff Base Complex. Yasemin Yahsi $^{\mathrm{a}, \mathrm{b}}$, Hulya Kara ${ }^{\mathrm{a}}$, Lorenzo Sorace ${ }^{\mathrm{b}}$ 